\title{
La actualidad de los partidos políticos en Colombia*
}

\author{
Germán Lozano Villegas** \\ Recibido: 3 de febrero de 2015 - Revisado: 15 de abril de 2015 \\ Aprobado: 20 de abril de 2015
}

\section{Resumen}

La presente disertacion desde la metodología de investigación cualitativa y desde una perspectiva histórico-descrptiva, pretende reflexionar sobre la naturaleza jurídica de los partidos politicos y su papel en el Estado colombiano. Lo anterior con la finalidad de comprender las deficiencias que dichas organizaciones han evidenciado en el marco de la política colombiana. Para tal efecto se desarrolla el marco normativo fundamental de la figura y se preven las principales tematicas de debate frente a dicha organización.

Palabras clave: partidos políticos, derechos politicos, democracia.

"El Artículo es producto del proyecto de investigación La historia de los partidos políticos, el cual hace parte de los proyectos de investigación institucionales de la Universidad Externado de Colombia. Dicho proyecto de investigación es financiado por la mencionada Universidad.

“* Doctor en Derecho, Universidad Externado de Colombia. Docente-Investigador vinculado al Departamento de Derecho Constitucional de la Universidad Externado de Colombia. Correo electrónico: germanlozanovillegas@yahoo.com 


\title{
Situation of Political parties in Colombia
}

\begin{abstract}
This dissertation from the qualitative research methodology and from a descriptive perspective - historical, aims to reflect on the legal status of political parties and their role in the Colombian state. This in order to understand the deficiencies that these organizations have demonstrated in the context of Colombian politics. To this end, the fundamental policy framework is developed figure and thematic discussion principals are anticipated against that organization.
\end{abstract}

Keywords: Political parties, political rights, democracy.

\section{A atualidade dos partidos políticos na Colômbia}

\section{Resumo}

A atual dissertação, desde a metodologia da pesquisa qualitativa e desde uma perspectiva histórico-descritiva, pretende refletir sobre a natureza jurídica dos partidos políticos e seu papel no Estado Colombiano. Nesse sentido tem como objetivo compreender as deficiências que estas organizações têm apresentado na política colombiana. Por isso se desenvolve o âmbito normativo fundamental da figura e se preveem as principais temáticas de debate no relacionado com esta organização.

Palavras-chave: partidos políticos, direitos políticos, democracia.

\section{Introduccion}

Es pertinente delimitar los principios constitucionales de la Carta de 1991 que gobiernan el concepto de los partidos políticos para después encontrar una definición que comprenda los preceptos constitucionales en concreto.

Los partidos políticos son una de las formas de organizaciones políticas1 existentes en Colombia que tienen vocación de permanencia pues se "conforman para desarrollar actividades políticas, procesos electorales y participar en asuntos públicos de manera general, y son los sujetos legitimados para acceder al poder político a

${ }^{1}$ Las organizaciones políticas existentes en Colombia son: los partidos políticos, los movimientos políticos, las agrupaciones políticas, las organizaciones sociales y los grupos significativos de ciudadanos. 
través de la postulación de candidaturas y listas en los procesos electorales"(Padrón, 2012 , p.), en donde la ley reserva su creación y desarrollo a los ciudadanos colombianos (artículos 40 y 108), pues los extranjeros residentes no pueden ejercer los derechos políticos, salvo el ejercicio del derecho al voto en elecciones municipales y distritales en los términos y con el cumplimiento de los requisitos establecidos en la ley, como lo dispone el artículo 100 de la Constitución Nacional.

Principalmente, en la parte dogmática de la Constitución, específicamente en el artículo 40, encontramos a los partidos políticos como una manifestación del derecho a la participación política, pero su creación y desarrollo están comprendidos dentro de la libertad de reunión y manifestación, libertad de expresión, asociación y pensamiento, consagrados en los artículos 20, 37 y 38 de la norma superior.

Otro principio que busca la regulación de los partidos políticos, es el pluralismo político, pues formalmente lo que se busca es la libertad de creación para garantizar un amplio número de organizaciones políticas para de esa forma prevenir el abuso por parte de los organismos del estado.

La Constitución de 1991 no establece mayores límites ni restringe los alcances del programa político pero sí exige organización democrática y unos principios rectores como la transparencia, moralidad, equidad de género etc., así: "Los partidos y movimientos políticos se organizarán democráticamente y tendrán como principios rectores la transparencia, objetividad, moralidad, la equidad de género y el deber de presentar y divulgar sus programas políticos" (Artículo 107 inc. 3).

Se enmarca en un concepto de democracia abierta, no impone límites al pluralismo y admite la incorporación de cualquier ideología siempre y cuando los que participen en la competencia para el acceso al poder no atenten contra las reglas de juego del sistema democrático y respeten los presupuestos para su existencia.

Partiendo de lo anterior, una definición coherente consistiría en entidades con personaría jurídica y de interés público que tienen como finalidad fomentar la democracia representativa y participativa de los ciudadanos (Lozan, 2012, p. 6).

\section{Requisitos}

La conformación de los partidos políticos no requiere de ningún requisitoen cuanto a estatutos, organización o juntas directivas, tampoco se han establecido requisitos para su funcionamiento, no obstante la Corte Constitucional (Corte 
Constitucional, 1994), a modo de ilustración de algunas funciones que son inherentes a los partidos políticos, mencionó las siguientes:

1. Movilizar a los ciudadanos con miras a su integración en el proceso político y a la reducción de la abstención electoral de modo que el sistema en su conjunto pueda aspirar a conservar su legitimidad y respetar el primado del principio mayoritario.

2. Convertir las orientaciones, actitudes y demandas de la población, expresas o latentes, en programas permanentes o coyunturales de acción política que se presentan como alternativas para ser incorporadas formalmente por las instancias públicas o que se destinan a alimentar la oposición frente al poder establecido.

3. Contribuir a la formación de una cultura política y al ejercicio responsable del sufragio, mediante la información al público relativa a los asuntos que revisten mayor trascendencia social.

4. Ofrecer a los electores las listas de personas entre las que pueden elegir a las personas llamadas a integrar y renovar los órganos estatales.

5. Garantizar a los electores que en proporción a sus resultados electorales y dependiendo de éstos, su capacidad organizativa podrá realizar los programas y propuestas presentadas.

Sin embargo, se puede decir que existe un requisito de publicidad para poder tener derecho a las prerrogativas estatales, este consiste en pedir el reconocimiento de la personería jurídica al Consejo Nacional Electoral (artículo 265.8), el cual otorgándola da derecho al goce de las siguientes prerrogativas:

1. Derecho de postulación de candidaturas y presentación de listas de candidatos.

2. Derecho a la financiación estatal para el funcionamiento y la realización de las campañas electorales.

3. Acceso a los medios de comunicación social del Estado en todo tiempo.

4. Los derechos que se desprenden del Estatuto de la Oposición.

Para tener derecho al reconocimiento de la personería jurídica se requiere obtener una votación no inferior al $3 \%$ de los votos emitidos válidamente en el territorio en las elecciones de Cámara o Senado y esta se perderá si teniéndola en las siguientes elecciones no llega a dicho porcentaje. Asimismo, el artículo 3 de la 
Ley 130 de 1994 contempló dos requisitos formales adicionales: la presentación de copia de los estatutos y la plataforma política. Estos requisitos son comunes y necesarios en la vida de cualquier organización política y presupuesto, pero no facultan a la Organización Electoral a hacer una revisión del contenido respectivo.

\section{Extinción y cancelación de los partidos políticos.}

El artículo 108 de la Constitución Política señala que la personería jurídica de los partidos políticos, se cancelaran si no alcanzan al menos una votación del $3 \%$ de los votos emitidos válidamente en el territorio nacional, en elecciones de Cámara de Representantes o Senado como se mencionó. Adicionalmente, también será causal de pérdida de personería jurídica no celebrar dentro de los dos años anteriores convenciones que posibiliten a sus miembros participar en la toma de decisiones de la organización política.

La pérdida de personería jurídica no implica que los partidos políticos queden extinguidos, (Hernández, 2006) pues estos pueden seguir actuando legalmente en la política colombiana a pesar de carecer de personería jurídica, los inhabilita para inscribir candidatos a elecciones y a gozar de ciertos beneficios como vimos en el acápite anterior.

\section{Debates en la Asamblea Nacional Constituyente de 1991 en cuanto al sistema de los partidos políticos.}

El objetivo del constituyente de 1991 en cuanto al tema de los partidos políticos era implantar el principio del pluralismo político. Se pretendía fomentar la inclusión de todos los sectores sociales y políticos en la competencia para el acceso al poder político y la participación en los asuntos públicos. Es la etapa de reconocimiento y garantía de los partidos políticos como contenido de sus derechos así como la regulación constitucional de otras vías para presentar una plataforma ideológica, como los movimientos políticos y grupos significativos de ciudadanos. En correlación con esto se amplía el derecho a elegir a todos los cargos públicos representativos, con la regulación de la elección popular de los Gobernadores.

Un objetivo adicional fue el fortalecimiento de la democracia representativa y la ampliación de sus espacios.. La superación de la crisis de la representación política es una condición esencial para abrir camino a espacios de participación ciudadana. 
Los proyectos radicados para el fortalecimiento de la democracia representativa coincidían en la necesidad de reglamentar las siguientes medidas:

1. Reconocimiento constitucional de los partidos y movimientos políticos; -rama electoral independiente y autónoma.

2. Establecimiento de la tarjeta electoral en todos los comicios.

3. Propuesta sobre la consagración del voto obligatorio.

4. Ampliación de inhabilidades e incompatibilidades para los candidatos a cargos de elección popular.

5. Elevación a la categoría constitucional del derecho a la oposición política y sus garantías.

En síntesis, las medidas consistían en ampliar el derecho a elegir y ser elegido, fomentar la creación de nuevos partidos políticos, darle centralidad a las organizaciones políticas y recuperar la vitalidad del Congreso de la República.

En cuanto a los cargos de máxima autoridad administrativa en los unicipios y los departamentos (las alcaldías y las gobernaciones) dejan de ser detentados por personas delegadas por el presidente de la República para ser de elección popular directa, al igual que para los miembros de las corporaciones de elección popular (Congreso de la República, Asambleas Departamentales, Concejos Municipales, y Juntas Administradoras Locales).

No solo se amplió el derecho al sufragio sino que también se contempló una acción de revocatoria del mandato para los cargos uninominales sujetos a voto programático (alcaldes y gobernadores) y la acción de pérdida de investidura de los congresistas con el fin de reforzar la responsabilidad política de los representantes.

\section{a. Reformas al regimen de partidos políticos en Colombia.}

A través del Acto Legislativo No. 1 de 2003 y el Acto Legislativo No. 1 de 2009 se realizaron dos reformas constitucionales que hacen parte del proceso de integración y fortalecimiento de las organizaciones políticas en el ordenamiento jurídico colombiano. 
Reforma del año 2003

La reforma del año 2003 tenía dos objetivos principales: fortalecer los partidos políticos y hacer más eficiente el trámite legislativo y de control político de las Cámaras.

Se pretendía un esquema de partidos menos dispersos, eliminar los partidos informales y establecer mecanismos eficaces de actuación colectiva, como las bancadas. El fortalecimiento del sistema electoral proporcional con lista única, la disciplina de partidos en las corporaciones de elección popular a través del establecimiento de la regla de bancadas, además de facultades sancionatorias de las organizaciones políticas con una amplia injerencia en el ejercicio del mandato parlamentario (facultades para suspender derechos de los congresistas y expulsar de la bancada respectiva).

Otras cambios establecidos en el Acto Legislativo No. 1 de 2003 en relación con las organizaciones políticas: podrán realizar consultas internas para la toma de decisiones y la escogencia de candidatos con el uso de los recursos que se derivan de la personería jurídica: financiación estatal y acceso a medios; la violación de los topes de financiación será causal de pérdida de investidura o del cargo; se financiarán con recursos estatales las consultas internas de las organizaciones políticas; las organizaciones políticas con personería jurídica tienen derecho a usar los medios de comunicación que utilizan el espacio electromagnético; las organizaciones políticas con personería jurídica que expresamente se declaren en oposición al Gobierno podrán acceder a los derechos que se desprenden del Estatuto de la oposición (art. 107, 109 y 111 constitucional).

Reforma del año 2009

La reforma en este año se generó en un momento histórico caracterizado por la infiltración de grupos armados al margen de la ley en la composición del Congreso de la República para el período 2002-2006.

Este escenario marcó los objetivos de la reforma constitucional para blindar a los órganos de representación popular y sancionar a organizaciones y candidatos cooptados por organizaciones ilegales.

Como consecuencia de lo anterior, se tomaron medidas tendientes a imponer más exigencias para la constitución de organizaciones políticas, hasta entonces, solo limitadas por la exigencia de la organización democrática interna. Las organizaciones 
deberán guiarse por los principios rectores de transparencia, objetividad, moralidad, equidad de género y el deber de presentar y divulgar su programa político.

Adicionalmente se aumentó el umbral para tener derecho a la asignación de curules (3\% de los votos para Senado y $50 \%$ del cociente electoral para Cámara) y para reconocimiento de la personería jurídica ( $3 \%$ de los votos emitidos en el territorio nacional para Cámara o Senado).

Por último, se refuerza la responsabilidad de los directivos de las organizaciones políticas por otorgar avales a candidatos o incluir en la lista electoral a personas que sean condenadas por tener vínculos con los grupos armados ilegales y denarcotráfico. Las sanciones a las organizaciones políticas pueden ser multas, suspensión o cancelación de la personería, eliminación de la financiación estatal, suspensión del acceso a los medio de comunicación o prohibición de presentar candidatos en la misma circunscripción (cargos uninominales) o suplir la vacante (corporaciones de elección popular)

\section{b. Efectos de las reformas al sistema de partidos}

El régimen electoral colombiano se podrá situar dentro de los llamados sistemas proporcionales, caracterizados por concederle a cada organización política un número de escaños en las corporaciones de elección popular, en la forma más aproximada posible al número de votos alcanzados. La Constitución Política de 1991 contempló el sistema de cociente electoral y de residuos, y las últimas reformas del sistema proporcional de umbral y cifra repartidora (Padron, 2015, p. 25).

Una parte de la doctrina constitucional une la existencia y práctica de los sistemas electorales proporcionales con la consolidación del trabajo en grupos en las cámaras legislativas de los respectivos países puesto que las listas presentadas por los partidos establecían la conformación de los grupos de parlamentarios o bancadas respectivas. No hay unanimidad en la doctrina constitucional europea para considerar a los sistemas electorales como presupuestos de existencia de los grupos parlamentarios. Ello, vale la pena repetirlo, porque los grupos parlamentarios han surgido y se han consolidado en estados con sistemas electorales mayoritarios, como es el caso de Inglaterra.

Sin embargo, no se discute la idea de que la existencia de los sistemas electorales proporcionales y las listas electorales presentadas por los partidos, favorecen el trabajo en grupos dentro de las Cámaras, siendo las listas un factor determinante 
para la conformación de los grupos o bancadas. Ello es así, porque el componente electoral es un elemento determinante para efectos de constituir las bancadas y con las prohibiciones expresas de que no pueden conformar grupos, congresistas que se hayan enfrentado a las elecciones.

En el ordenamiento jurídico colombiano el objetivo principal era fortalecer los partidos políticos, como organizaciones sólidas que encaucen el pluralismo social. Y para la consecución de este objetivo, como ya se anotó, se han implementado dos medidas principales: por un lado, la reforma al sistema electoral por listas electorales -abiertas o cerradas- y, por otro lado, la regla de actuación en bancadas al interior de las corporaciones de elección popular (Congreso de la República, Asambleas Departamentales y Concejos Municipales).

Se evidencia una gran diferencia en el caso de algunos estados europeos en los cuales los grupos parlamentarios se consolidan con la aparición del sistema de listas electorales; en el caso colombiano, las bancadas resultan una medida impuesta por el Congreso, cuyas usos y costumbres no responden a la actuación política organizada de sus miembros.

Cada vez que se han hecho intentos de fortalecimiento de partidos y de disciplina de grupo, se ha establecido la posibilidad de apartarse de los partidos, de fusionarse o de crear uno nuevo. Por ejemplo, en las dos últimas reformas políticas de 2003 y 2009, se contempló un período de transición en el cual se podían unir los partidos políticos existentes y crear una nueva organización, o se podía reunir un número determinado de senadores y representantes para crear un partido político diferente.

Las listas deben superar un porcentaje para conservar o concederle la personería jurídica al partido y/o movimiento político. El umbral consiste en el $3 \%$ de los votos emitidos válidos en el territorio nacional en elecciones de Senado o Cámara de Representantes, con la excepción de la circunscripción de minorías étnicas y políticas, para las que solo bastará que hayan obtenido representación en el Congreso.

Uno de los principales efectos de la puesta en marcha del sistema electoral, de listas, abiertas o cerradas, umbral y cifra repartidora ha sido la disminución de los partidos y movimientos políticos existentes en el país. Después de las elecciones de 2006, de los 62 existentes solo mantuvieron su personería 17; luego de las elecciones de 2010, solo quedaron 12 partidos y movimientos políticos. La ampliación de umbrales aún más estricto en la última reforma parece apuntar a que se reduzca la oferta de organizaciones políticas. 
La elaboración de las listas electorales tiene límites formales y sustanciales. a) Los formales, corresponden al hecho de no poder presentar más candidatos que el número de puestos a proveer en la respectiva elección; ningún candidato puede estar en más de dos listas electorales; no se pueden incluir candidatos que hayan sido condenados durante el período del cargo por delitos relacionados con la vinculación a grupos armados ilegales y de narcotráfico, o delitos contra los mecanismos de participación democrática o de lesa humanidad. b) Límites sustanciales, indican que la confección de las listas electorales debe responder a procesos democráticos y que se respeten los principios de la transparencia, objetividad, moralidad y equidad de género.

La confección de las listas electorales determinará la conformación de las bancadas en las corporaciones de elección popular. De esto se desprende el siguiente apartado del artículo 108 constitucional

Los miembros de las Corporaciones Públicas elegidos por un mismo Partido o Movimiento Político o grupo significativo de ciudadanos actuarán en ellas como bancada en los términos que señale la ley y de conformidad con las decisiones adoptadas democráticamente por estas (art. 108 inc. 6).

A las listas que alcancen el umbral, y con el fin de garantizar la equitativa representación de los partidos y movimientos políticos y grupos significativos de ciudadanos, las curules de las corporaciones públicas se distribuirán mediante el sistema de cifra repartidora.

La repartición de curules entre las listas determinará la conformación de las bancadas al interior del Congreso de la República y serán los partidos y movimientos políticos, los que establezcan en sus estatutos las reglas de actuación, el proceso de toma de decisiones y los asuntos de conciencia, que permitan disentir de la decisión de grupo.

Una vez se haya efectuado el conteo de los votos, la Registraduría Nacional del Estado Civil emitirá el resultado final de las elecciones. Con base en este informe se delimita cómo quedarán conformadas las bancadas en el Senado y la Cámara de Representantes. Es la lista electoral la que determina los miembros de la bancada respectiva. En el marco de la libertad de asociación, se le otorga la potestad a cada organización política para que establezca el régimen de actuación y régimen disciplinario de cada una de sus bancadas. 


\section{Los partidos políticos en la actualidad colombiana}

Es razonable argumentar que gracias a los efectos potenciales de las recientes transformaciones institucionales y reformas al sistema electoral, los partidos políticos están encaminados a convertirse en partidos programáticos, más coherentes, concretos y mejor definidos en su naturaleza organizacional, programática y en su estrategia electoral. Por otro lado, se debe caracterizar la presencia de nuevos m..ovimientos partidistas que se alejan del bipartidismo histórico y que han venido permeando la arena política colombiana, especialmente a partir de la Constitución de 1991.

Esta libertad para crear las organizaciones políticas se tradujo en el tránsito del sistema bipartidista al sistema multipartidista, el cual ha soportado pluralidad de críticas en razón a que constituye un peligro que puede fácilmente desembocar en fines diferentes a los de la Constitución. De esta forma un amplio sector de la doctrina, ha definido el multipartidismo como la

atomización de los partidos tradicionales -Liberal y Conservador- y fragmentación de las minorías políticas (agrupaciones políticas, religiosas, étnicas y regionales), donde no se habla de partidos políticos sino de microempresas electorales, entendidas como empresas electorales que se disputan el campo de la representación política (Pizarro, 2001, pp. 96-126).

De la misma forma negativa como se ha definido al multipartidismo, este tuvo su lugar en Colombia, pues fue palpable que el tránsito del bipartidismo al multipartidismo se caracterizó por la división de los partidos tradicionales y la fragmentación de las minorías políticas. Por consiguiente, en la actualidad no es posible hablar en Colombia de verdaderos partidos políticos sino de microempresas electorales, en la medida que son empresas individuales que se disputan el campo de la representación política.

El reparto de avales a múltiples listas entregados por los partidos tradicionales dibujó un multipartidismo engañoso. El sistema de partidos puede ser analizado desde el punto de vista general, exterior y desde el interior de cada partido. En este punto se analizan las subunidades del partido: fracciones y facciones. Las fracciones tienen organización, estabilidad, significación electoral, identidad propia entorno a un líder, pero mantienen una gran dependencia del partido. Y las facciones tienen una organización endeble. 
En Colombia los partidos tradicionales han transitado de un sistema de partidos dominados por fracciones internas de orden nacional a un sistema de partidos totalmente atomizado en facciones personalistas. En esta transición se han desdibujado las principales funciones de los partidos: a) formular programas con el objeto de agregar, articular y representar intereses existentes en la sociedad; b) organizar las campañas electorales; c) reclutar los líderes políticos llamados a ocupar los principales cargos públicos; y d) participar en la formulación e implementación de políticas públicas o ejercer desde la oposición el rol de alternativa.

En conclusión, el multipartidismo nunca se dio, por el contrario, se presentó una división de las organizaciones, trayendo como resultado unas organizaciones desmembradas de los partidos políticos tradiciones, lo que es entre otras cosas, una situación que Colombia ha padecido desde los inicios de su independencia como por ejemplo con la facción de los independentistas. Por consiguiente, no es el partido el que elige al candidato sino al revés, lo que trajo consigo la proliferación de listas y de avales, a lo que contribuyó la no prohibición de la doble militancia.

Es muy probable que la crisis de la democracia y el desprestigio de los partidos políticos se deba a lo anteriormente expuesto, y adicionalmente por unos factores que se ha determinado a través de encuestas realizadas en los últimos 10 años, tendientes a demostrar cómo la población no cree en los partidos ni en los políticos:

- La desaparición del debate y la confrontación de las ideas y su obvia consecuencia de desconocimiento de las manifestaciones propias de los cambios de la sociedad.

- Generalización y presencia masiva de los modernos medios de comunicación.

- Dominio y sometimiento del factor dinero sobre la política.

- Desproporción entre las ofertas de los aspirantes y las realizaciones de los elegidos.

- ineficiencia e ineficacia del trabajo de las leyes parlamentarias y por ende de las leyes expedidas.

- Dominio de los parlamentarios en la vida institucional del partido (Giraldo, F.; Muñóz, P., 2014, p. 21).

\section{Elementos comunes a los partidos políticos actuales}

- Convenciones nacionales: se considera un elemento común a todos los partidos políticos toda vez que son consideradas como requisitos vinculantes en la normatividad colombiana. Así el Acto Legislativo 01 de 2009 estipula 
como causal de pérdida de personería jurídica de los partidos el hecho de no celebrar convenciones que influyan en la toma de decisiones por lo menos durante cada dos años.

- Conformación de listas: todos los partidos o movimientos políticos deben conformar listas por lo que el Acto Legislativo 01 de 2009 (artículo 11) señala que "para todos los procesos de elección popular, los partidos políticos presentarán listas y candidatos únicos, cuyo número de integrantes no podrá exceder el de curules o cargos a proveer en la respectiva elección”.

- Régimen de bancadas: a todos los partidos políticos se les aplica el mismo régimen de bancada establecido por la Ley 974 de 2005, que estipula que un mismo partido tendrá la posibilidad de elegir a miembros de corporaciones públicas para que actúen en grupo, coordinadamente y a través de mecanismos democráticos.

- Principios generales: aunque cada partido político tiene suficiente autonomía para determinan bajo qué principios va a regir su ideología existen unos principios comunes a todos los partidos, que a su vez son exigidos en diferentes leyes colombianas. El principio de transparencia establecido en la Ley 1475 de 2011, que se traduce en mantener informados a los miembros del partido acerca de las actividades políticas, administrativas y financieras que se realicen dentro del movimiento. Esto se traduce en la obligación que tienen todos los partidos de rendir cuentas ante el Consejo Nacional Electoral dentro de los primeros cuatro meses de cada año.

Como otros principios comunes encontramos los principios de autonomía, organización y coordinación de los partidos, así como el de la Equidad de Género, este último ha sido regulado por el Acto Legislativo 01 de 2009, al extender las cuotas para los partidos políticos y la conformación de listas a cargos de elección popular de la siguiente manera:

Las listas donde se elijan cinco o más curules para corporaciones de elección popular o las que se sometan a una consulta, exceptuando su resultado, deberán conformarse por mínimo un $30 \%$ de uno de los géneros (masculino o femenino).

- Sentido de pertenencia e identificación ciudadana respecto de los partidos políticos: estudios han revelado que los colombianos no se sienten identificados con ningún partido político actual en el país, así lo determinó 
puntualmente el Barómetro de las Américas de 2012, según el cual de los 25 países estudiados Colombia es el quinto país que menos confía en sus partidos. Dicha desconfianza ha tenido que ver precisamente con el desconocimiento del principio de transparencia de los mismos y por fenómenos sociales tales como el conflicto armado, la corrupción y el abuso del poder.

- Consultas populares: respecto a este tema también se aplica el mismo régimen normativo para todos los partidos, de esta manera la Ley 1475 de 2011 ha establecido que las consultas populares son mecanismos de participación democrática que pueden ser utilizados por los partidos con la finalidad de adoptar decisiones internas o escoger candidatos a cargos corporativos en elecciones populares. Dichos mecanismos a su vez deben cumplir con los siguientes requisitos, según lo establecido por la Ley 1475: 1) El Estado contribuirá a su financiamiento a través del sistema de reposición de gastos por votos obtenidos 2) La Organización Electoral debe colaborar en la organización y realización de las consultas, para lo cual suministrará las tarjetas electorales o instrumentos de votación, así como realizar el escrutinio. 3) Las consultas realizadas con el fin de elegir candidatos a un mismo cargo o corporación deberán realizarse en la misma fecha por todos los partidos interesados en hacer uso de dicho mecanismo. 4) Los precandidatos en una consulta no pueden inscribirse como nuevos candidatos en el proceso electoral. 5) Los resultados de las consultas son obligatorios para todos los partidos. 6) Le queda prohibido a cada partido apoyar o inscribir candidatos distintos a los seleccionados por dicho mecanismo.

- Reconocimiento de género: aunque este tema se enuncia dentro del acápite de los principios generales, es importante resaltar que todos los partidos políticos deben promover la misma participación política para ambos géneros, sea masculino o femenino, lo que implica que no haya discriminaciones por razón de género, como tampoco de religión, ideología u orientación sexual.

\section{a. Partidos tradicionales}

Las nuevas dinámicas políticas y electorales de los partidos tradicionales (conservador y liberal) son el resultado de los cambios surgidos después de la expedición de la Constitución Política de Colombia de 1991, específicamente lo que tiene que ver con las dinámicas electorales y el sentido de pertenencia de los partidos políticos. Así, a partir del año 2002 los partidos tradicionales empezaron a reducirse y a perder 
poder frente a la ausencia de concertación de grandes porcentajes de votos que se conseguían a través del clientelismo y frente al surgimiento de nuevos partidos políticos, en su mayoría de izquierda, los cuales habían logrado mayor acogida por los ciudadanos. Estos cambios están dados fundamentalmente por las prohibiciones que incluyó la Carta constitucional respecto de la organización de los partidos, a saber por ejemplo: se prohíbe la acumulación de mandatos; se establece elección popular de gobernadores; son abolidos los auxilios parlamentarios; los diputados y congresistas ya no pueden ocupar cargos administrativos, como tampoco pueden ocupar cargos en juntas directivas y consejos de administración.

Aunque sigue existiendo clientelismo y arraigo hacia los partidos políticos tradicionales, hay más espacios de competencia, menor concentración de poder, procedimientos menos susceptibles del control clientela, y mayores disputas facciones por los recursos limitados, por esto último y debido a que hay más actores en el mercado electoral se genera una mayor competencia intrapartidista.

Por su parte, la identificación partidista continúa incidiendo en las dinámicas electorales pero de diferente forma, puesto que el sentido de pertenencia de la población respecto de los partidos presenta una tendencia decreciente desde la década de los años ochenta.

De esta manera, los resultados electorales de los partidos colombianos expresados en la estructura parlamentaria del Senado comparando 2006 y 2010, reflejan el fuerte agrupamiento del sistema de partidos. Esto es quizás el más grande logro de las reformas de 2003 y 2009, como consecuencia de la última se permitió que los congresistas se trasladaran de partido, lo que generó aún más la segregación de partidos diferentes al liberal y al conservador.

$\mathrm{El}$ análisis expuesto anteriormente, no solamente explica la evolución de los partidos tradicionales sino que también explica la inclusión de los llamados partidos políticos actuales de Colombia, que como se explica a continuación, se expresan a través de las figuras políticas de oposición como los de derecha e izquierda.

\section{b. Partidos políticos originados por el multipartidismo}

El multipartidismo en Colombia, como la misma palabra lo indica, hace referencia a la pluralidad de partidos políticos existente en la actualidad de nuestro país, dichos movimientos políticos se rigen por elementos comunes exigidos por la ley, pero son totalmente autónomos e independientes. Por lo anterior, la forma más 
sencilla de explicar las nuevas tendencias partidistas es a través de los movimientos de oposición, entendidos de la siguiente manera:

\section{- Oposición de derecha}

Se conoce como derecha al segmento del espectro político que acepta o promulga las diferencias sociales como algo secundario frente a la izquierda, que persigue una mayor igualdad o participación política. No existe una definición estricta de derecha aunque dadas un conjunto de dicotomías como, libertad individual frente a colectivismo, confesionalidad frente a laicismo, propiedad privada frente a propiedad pública de ciertas actividades económicas, igualdad de oportunidades frente a igualdad de resultados, tradicionalismo frente a reformismo social, conservadurismo frente a liberalismo, la derecha se decanta estadísticamente por la primera de ellas en mayor proporción que la izquierda. Actualmente, el discurso político de la mayor parte de fuerzas de derecha se inclina a favorecer la riqueza a través de la libre competitividad.

No obstante, en Colombia, quizás con excepción de los partidos liberal y conservador, la creación y fundación de movimientos políticos de derecha han obedecido a razones que se podrían clasificar como de coyuntura, circunstanciales, o por motivos de personalidades destacadas como Álvaro Uribe Vélez, Antanas Mockus, Enrique Peñalosa, Piedad Córdoba o Germán Vargas Lleras, entre otros.

La oposición de derecha, liderada por Álvaro Uribe quien llegó al Congreso con una bancada fuerte que le ha permitido contraponerse con fuerza institucional al gobierno de 2014-2018, del presidente Juan Manuel Santos. Por fuerza de opinión que tiene este movimiento, es la oposición más grande en el actual Congreso. Y ante las dificultades de la izquierda, podría ser ese sector el que tome el relevo de oposición que antes ejercían los partidos liberal de 2002 a 2010 y la izquierda con el PDA desde 2002.

\section{- Oposición de izquierda}

El concepto de izquierda política se refiere a un segmento del espectro político que considera prioritario el progresismo y la consecución de la igualdad social por medio de los derechos colectivos (sociales) circunstancialmente denominados derechos civiles, frente a intereses netamente individuales (privados) y a una visión tradicional o conservadora de la sociedad, representados por la derecha política. En general, tiende a defender una sociedad aconfesional o laica, internacionalista progresista, igualitaria e intercultural. 
La izquierda en Colombia desde 1958 con la excepción de los mejores momentos del Polo Democrático Alternativo en las elecciones locales de 2003 en Bogotá y Nariño y las de 2007 en Bogotá, así como las legislativas y presidenciales de 2006, ha estado en una condición de fuerza marginal con escasos recursos institucionales, fragmentada entre extremo y girando en torno a debates ideológicos con fuertes dosis de dogmatismo que se salvan tradicionalmente con fracturas organizativas. Desde el inicio del Frente Nacional hasta el presente se cuenta por docenas las organizaciones políticas de izquierda.

\section{- Oposición ciudadana}

Por las posturas ideológicas y por su tradición que existe, una especie de abanico de organizaciones que no hacen parte de la coalición de gobierno y que son ser especialmente proclives a este tiene una postura independientemente moderada, poco beligerante y a veces colaborativa con el gobierno. Es una oposición difusa que se representa en partidos políticos como MIRA, ASI o los sectores mayoritarios del partido Alianza Verde, entre otros. Algunos de estos movimientos tienen dirigentes que se presentan como políticos con pena de serlo y adoptan posturas críticas ante la opinión pública como si fuesen anti políticos.

Sin embargo, lo más significativo en perspectiva del desgaste de los partidos políticos de origen tradicional y para las elecciones legislativas, es la explosión sorpresiva de 26 y 54 grupos significativos de ciudadanos que lucharán para obtener curules en el Senado y la Cámara de Representantes respectivamente.

Estos grupos de ciudadanos constituidos y promovidos con fines electorales son de diverso orden y origen: campesinos, desplazados, disidentes de otros partidos, promotores del voto en blanco y otros que son políticamente independientes de los partidos convencionales.

Las probabilidades de que lleguen a las corporaciones no son altas dadas las exigencias del sistema electoral en lo que respecta a umbrales, pero su participación tendrá como consecuencia el aumento de participación electoral y por tanto el aumento del umbral, lo que además incrementará el número de los movimientos y electores frustrados.

\section{Conclusiones}

Es fundamental el replanteamiento del sistema de partidos en Colombia, para que se garantice la defensa del sistema democrático y el bienestar de los 
administrados, creando conductos de opiniones efectivos para defender necesidades y valores de la sociedad, y lo más importante, permitir una interacción institucional y competitiva para lograr una sana vida política, de esa forma se ofrecerán mejores programas al país.

Es indispensable la construcción de un efectivo control institucional y jurídico, para evitar la desviación de prácticas democráticas y el apoderamiento de las instituciones o corporaciones públicas del Estado, lo cual ocurre cuando los intereses de los partidos políticos están por encima de los intereses y fines del Estado. Para de ese modo llegar a extinguir practicas tan comunes como la destinación de dineros del erario público a objetivos distintos de los previstos en la ley o plan de desarrollo.

Colombia necesita una visión de una nueva izquierda que revitalice la discusión programática y la plataforma de los partidos en el escenario nacional, que llegue a cuenta con una organización política, democrática y participación ciudadana y apoyo estatal necesario; de manera que contribuya a un efectivo pluralismo político en donde importen más las ideas que los "cacicazgos” y las "dinastías políticas", y que finalmente redunde en una libertad política del elector quien debidamente informado pueda participar al interior de los partidos y en las juntas electorales con plena convicción y libertad de su alternativa política.

\section{Referencias}

Bergquist, C. W. (1981). Café y conflicto en Colombia, La guerra de los mil días, sus antecedentes $y$ consecuencias, 1886-1904. Medellín: FAES.

Bushnell, D., y Montilla, C. (1996). Colombia, una nación a pesar de si misma: de los tiempos precolombinos a nuestros días. Bogotá, Ed. Planeta Colombia S.A.

Corte Constitucional, Sentencia C-089 de 1994, Fundamento No. 17.

Corte Constitucional, Sentencia C - 1153 de 2005.

de Mosquera, T. C. (1984). Los partidos politicos en Colombia. Bogotá, Editorial Incunables.

Guerrero, J. (2007). Los años del olvido: Boyacá y los orígenes de la violencia. Universidad Pedagógica y Tecnológica de Colombia.

Giraldo, F., (2003). Sistema de Partidos Politicos en Colombia. Bogotá. CEJA.

Giraldo. F. y Muñoz, P. (2014). Partidos Politicos en Colombia: Evolución y Prospectiva. Bogotá. Ed. Hubert Gehing.

Hernández, B. A. (2006). Regulación jurídica de los partidos políticos en Colombia.Regulación jurídica de los partidos políticos en América Latina, México DF: UNAM, 331-364. 
Leongómez, E. P. (2001). Colombia: ¿̨renovación o colapso del sistema de partidos? Colombia antes los retos del siglo XXI: desarrollo, democracia y paz. Salamanca, Ediciones Universidad de Salamanca, Ed. $1^{\text {a }}$

Lozano, V. G. (2014). Los Partidos Políticos en Colombia: Marco Jurídico de Creación, Registro, Funcionamiento y Extinción. México D.F. UNAM.

Melo, M. (1981). Café y conficto en Colombia 1886-1910: La guerra de los mil días, sus antecedentes y consecuencias. Medellín, Fondo Rotatorio de Publicaciones FAES.

Padrón, P. F. (2012). Las organizaciones politicas en Colombia: reconocimiento constitucionaly proceso de fortalecimiento. En J. Stefan (ed.) 20 años de la constitución colombiana: logros, retrocesos, y agenda pendiente, Bogotá, Fundación Konrad Adenauer.

Padrón, P. F. (2015). Concepto y Función de los Grupos Parlamentarios en la Reforma de la Representación Politica en Colombia. Bogotá, Universidad Externado de Colombia.

Plaza, V. M. (2011). El Frente Nacional, Bogotá. Editorial Temis S.A.

Romo, R. F. (xxxx). Fracción y partido. Indagaciones sobre la historia de los conceptos [en línea] recuperado de http://meme.phpwebhosting.com/ migracion/rimd/documen tos_miembros/11700Facci\%F3n\%20y\%20Partido.pdf

Rousseau, J. J. (1998). “El contrato social” Libro cuarto. Traducción: Leticia Halperin Donghi, Buenos Aires, Editorial Losada

Safford, F. R. (2012). Acerca de las interpretaciones socioeconómicas de la política en la Colombia del siglo XIX: variaciones sobre un tema. [el línea] recuperado de http:// www.revistas.unal.edu.co/index.php/achsc/article/view/36148

Sánchez, G. y Peña, M. A. (2001). Memoria de un país en guerra: los mil dias, 1899-1902. Bogotá, Editorial Planeta Colombia S.A., Edición 1a, 